Correction

\title{
Correction: Kaushal et al. Repurposing Niclosamide for Targeting Pancreatic Cancer by Inhibiting Hh/Gli Non-Canonical Axis of Gsk3ß. Cancers 2021, 13, 3105
}

Jyoti B. Kaushal ${ }^{1}$ (D), Rakesh Bhatia ${ }^{1}$, Ranjana K. Kanchan ${ }^{1}$, Pratima Raut ${ }^{1}$, Surya Mallapragada ${ }^{2}$, Quan P. Ly $^{3}$, Surinder K. Batra ${ }^{1,4}\left(\mathbb{D}\right.$ and Satyanarayana Rachagani ${ }^{1, *(\mathbb{D})}$

1 Department of Biochemistry and Molecular Biology, University of Nebraska Medical Center, Omaha, NE 68198, USA; jyoti.kaushal@unmc.edu (J.B.K.); rocky.bhatia@unmc.edu (R.B.); ranjana.kanchan@unmc.edu (R.K.K.); pratima.raut@unmc.edu (P.R.); sbatra@unmc.edu (S.K.B.)

2 Department of Chemical and Biological Engineering, Nanovaccine Institute, Iowa State University, Ames, IA 50011, USA; suryakm@iastate.edu

3 Department of Surgical Oncology, University of Nebraska Medical Center, Omaha, NE 68198, USA; qly@unmc.edu

4 Fred \& Pamela Buffet Cancer Center, Eppley Institute for Research in Cancer and Allied Diseases, University of Nebraska Medical Center, Omaha, NE 68198, USA

* Correspondence: srachagani@unmc.edu

check for updates

Citation: Kaushal, J.B.; Bhatia, R.; Kanchan, R.K.; Raut, P.;

Mallapragada, S.; Ly, Q.P.; Batra, S.K.; Rachagani, S. Correction: Kaushal et al. Repurposing Niclosamide for Targeting Pancreatic Cancer by Inhibiting Hh/Gli Non-Canonical Axis of Gsk3 $\beta$. Cancers 2021, 13, 3105. Cancers 2021, 13, 5591. https:// doi.org/10.3390/cancers13225591

Received: 22 September 2021 Accepted: 8 October 2021

Published: 9 November 2021

Publisher's Note: MDPI stays neutral with regard to jurisdictional claims in published maps and institutional affiliations.

Copyright: (C) 2021 by the authors Licensee MDPI, Basel, Switzerland. This article is an open access article distributed under the terms and conditions of the Creative Commons Attribution (CC BY) license (https:// creativecommons.org/licenses/by/ $4.0 /)$.
The authors would like to make a correction to their published paper [1]

On page 13, in the online version of this article, the "fluorescence image in Figure 4D" was mistakenly misplaced with a fluorescence image of Figure $2 \mathrm{C}$ during submission/ revision. The authors would like to change Figure 4 with a new corrected version (with replaced Figure 4D), which is listed below:

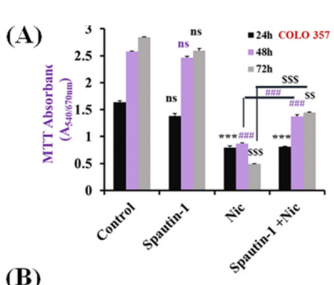

(B)

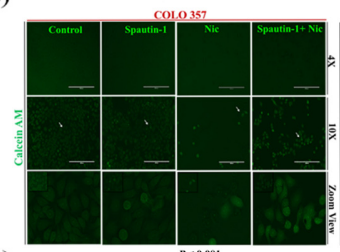

D)

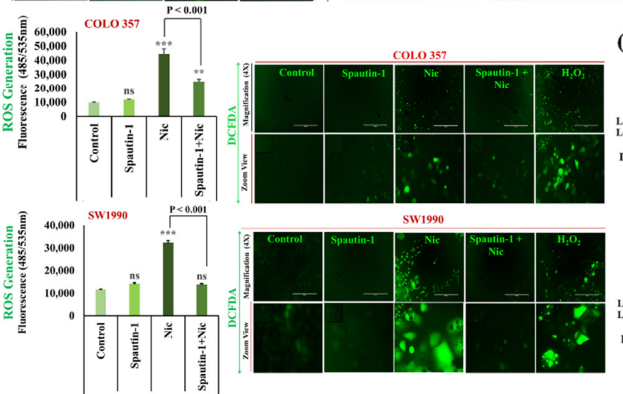

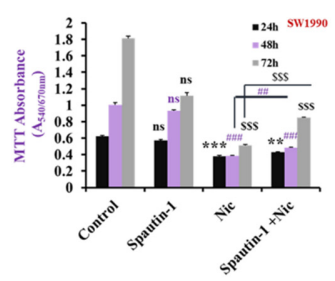

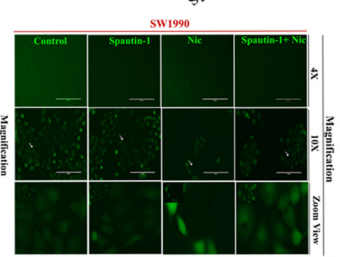

(E)

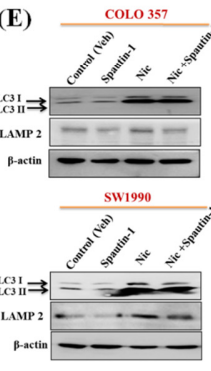

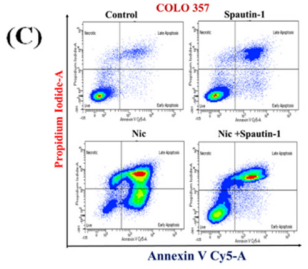
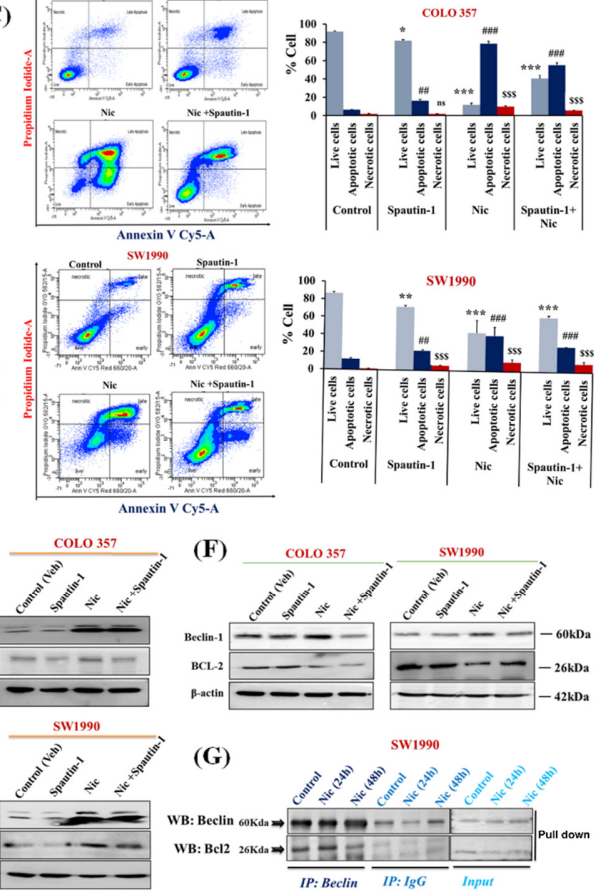

Figure 4. Nic-induced autophagy leads to PC cell death by disrupting Beclin1-BCL2 interaction. (A) Effect of functional blockage of autophagy via spautin-1 on Nic-treated PC cells resulted in growth promotion. COLO 357 and SW1990 cells were pretreated with spautin-1 for $2 \mathrm{~h}$, followed by Nic $(10 \mu \mathrm{M})$ for 24,48 , and $72 \mathrm{~h}$ and cell viability was assessed by MTT assay. Values are expressed as mean 
$\pm \operatorname{SEM}(n=3), p$ values: ${ }^{* *} p<0.001,{ }^{* *} p<0.01$ vs. control $(24 \mathrm{~h}) ; p$ values: ${ }^{\# \#} p<0.001,{ }^{\# \#} p<0.001$ vs. control (48 h); $p$ values: $\$ \$ \$<0.001, \$ \$ p<0.001$ vs. control (72 h). (B) Representative images showing the Calcein-AM-stained cells, original magnification $4 \times ; 10 \times$. (C) Protective effect of autophagy inhibition on Nic-induced apoptosis was determined by flow cytometric analysis of PC cell lines after staining with annexin-V Cy-5/PI $\left(\mathrm{AV}^{+} / \mathrm{PI}\right.$-intact cells; $\mathrm{AV} / \mathrm{PI}^{+}$—nonviable/necrotic cells; $\mathrm{AV}^{+} / \mathrm{PI}$ and $\mathrm{AV}^{+} / \mathrm{PI}^{+}$-apoptotic cells) in different groups, i.e., spautin-1, Nic and combination of Spautin-1 and Nic (left panel). Quantitative analysis of these micrographs was shown as mean \pm SEM, $p$ values: ${ }^{* * *} p<0.001,{ }^{* *} p<0.01,{ }^{*} p<0.05$ vs. live control cells; ${ }^{\# \# \#} p<0.001,{ }^{\# \#} p<0.001$ vs. apoptotic control cells; $\$ \$ p<0.001$ vs. necrotic cells (right panel). (D) Intracellular ROS levels in cells treated with spautin-1, Nic and their combination were evaluated using DCFDA fluorogenic dye (10 $\mu \mathrm{M}$ for $30 \mathrm{~min}$ ) by measuring fluorescence at 485/535 $\mathrm{nm}$ (excitation/emission) using a fluorescent plate reader (left panel). The results are expressed as relative fluorescence intensity units. Values are expressed as mean $\pm \operatorname{SEM}(n=3), p$ values: ${ }^{* *} p<0.001,{ }^{* *} p<0.01$ vs. control. Fluorescence imaging was performed in these cells stained with DCFDA (right panel), original magnification $4 \times$. (E,F) Representative western blot images showing the expression of LC3I/II and LAMP2 (E); Beclin-1 and BCL2 (F) in COLO 357 and SW1990 cells treated with spautin-1, Nic and their combination. Membrane was stripped and re-probed with $\beta$-actin to correct for loading control. (G) Representative western blot images showing the expression of Beclin-1 and BCL2 in cells treated with Nic $(10 \mu \mathrm{M} ; 24$ and $48 \mathrm{~h})$ and lysates were immunoprecipitated with Beclin-1 antibody and analyzed by western blotting for BCL2 interaction.

The change does not affect the scientific results.

The rest of the manuscript does not need to be changed. The authors would like to apologize for any inconvenience caused. The original manuscript has been updated.

\section{Reference}

1. Kaushal, J.B.; Bhatia, R.; Kanchan, R.K.; Raut, P.; Mallapragada, S.; Ly, Q.P.; Batra, S.K.; Rachagani, S. Repurposing Niclosamide for Targeting Pancreatic Cancer by Inhibiting Hh/Gli Non-Canonical Axis of Gsk3ß. Cancers 2021, 13, 3105. [CrossRef] [PubMed] 